\title{
BMJ Open Sociocultural aspects of takeaway food consumption in a low-socioeconomic ward in Manchester: a grounded theory study
}

\author{
Jennifer Blow, ${ }^{1}$ Sumaiya Patel, ${ }^{1}$ Ian G Davies, ${ }^{2}$ Rebecca Gregg ${ }^{1}$
}

To cite: Blow J, Patel S, Davies IG, et al. Sociocultural aspects of takeaway food consumption in a lowsocioeconomic ward in Manchester: a grounded theory study. BMJ Open 2019;9:e023645. doi:10.1136/ bmjopen-2018-023645

- Prepublication history and additional material for this paper are available online. To view these files, please visit the journal online (http://dx.doi org/10.1136/bmjopen-2018023645).

Received 16 April 2018 Revised 2 January 2019 Accepted 15 January 2019

A) Check for updates

(C) Author(s) (or their employer(s)) 2019. Re-use permitted under CC BY-NC. No commercial re-use. See rights and permissions. Published by BMJ.

${ }^{1}$ Health Professionals, Manchester Metropolitan University Faculty of Health Psychology and Social Care, Manchester, UK

${ }^{2}$ Education, Health and Community, Liverpool John Moores University, Liverpool, UK

Correspondence to Dr Rebecca Gregg; r.gregg@mmu.ac.uk

\section{ABSTRACT}

Objectives Takeaway foods form a growing proportion of the UK diet. This consumption is linked with poor health outcomes due to their adverse nutritional profile. However, there is little research regarding the sociocultural context surrounding the consumption of takeaway meals. This research aimed to explore the sociocultural factors that influence the consumption of takeaway foods.

Design The study employed constructivist grounded theory (GT) methodology. Data were collected using oneto-one semi-structured interviews from an inner-city area of Manchester (Rusholme). Data sorting and analysis was implemented using the GT constant comparative method. Setting Rusholme, Manchester, UK.

Participants Adult participants (aged 18 to 65 years) consuming takeaway meals at least once/month were recruited using social media and community settings. Results 13 participants were interviewed (female 69\%, mean age $=38$ years). Three superordinate themes were derived from data: social factors, personal factors and resources. Social Factors included the influence of routines and traditions, influential others and a sense of community in the bonding and affirming of relationships. Personal Factors explored the subordinate themes of controlling damage and values relating to food choice. The third theme 'Resources' included time, availability, cost and quality.

Conclusion This study shows the sociocultural influences on food choice decisions are complex and may go beyond access and availability. Any policy change to limit takeaway consumption should acknowledge these vital processes in food choice to inform targeted effective approaches.

\section{INTRODUCTION}

The UK has a well-recognised childhood and adult obesity epidemic, amplified in lower socioeconomic groups. ${ }^{1}$ Of particular concern is the availability and access to takeaway meals, which are known to contain an adverse nutritional profile. ${ }^{2} 3$ Within disadvantaged areas they have been linked with increased consumption ${ }^{4}$ and a rise in obesity. ${ }^{56}$ Takeaway and fast foods now make up approximately $21 \%$ of the UK diet with

\section{Strengths and limitations of this study}

- The methods used here are ideally placed to understand the complexity of the interaction between food choices, geographical environment and socioeconomic factors.

- Very little is known about people's experiences of take away foods. Research in this area is essential to inform appropriate behaviour change interventions that address a growing need for takeaway meals.

- The findings are specific to the people involved in this study; however, the use of grounded theory allows themes to transcend beyond basic description and to resonate with other similar situations and locations.

adults aged younger than 30 years and children being the most frequent consumers. ${ }^{7}$

Manchester City Council (MCC) has been ranked eighth of 325 local authorities in England for the highest quantity of takeaway outlets per 100000 people by local authority and contains a significantly higher number of outlets than the England average. ${ }^{8}$ The Rusholme ward of Manchester is a densely populated residential area, with a large proportion of young students and South Asian residents. Rusholme comprises many restaurants and takeaway establishments known locally as the 'Curry Mile'. The National Planning Policy Framework $^{9}$ suggested that local authorities could use planning permission to control the proliferation of takeaway outlets. MCC have therefore proposed to deny planning permission for new takeaway outlets in particular where they are already densely concentrated near to schools, as well as controlling opening hours. ${ }^{8}$

Altering the physical takeaway food environment is one method of taking control of the physical environmental influences on food choice yet research from Australia and the USA show that presence of fast-food and 
or takeaway outlets are not always associated with their consumption. ${ }^{10-13}$ Although a Canadian study showed fast-food consumption was attributable to proximity of outlets, ${ }^{14}$ two recent systematic reviews show that the presence of additional grocery outlets and thus widening food access does not necessarily correlate with long-term changes in food choices. ${ }^{1516}$ Therefore, this suggest wider sociocultural (such as cultural identity, social norms, attitudes and beliefs) and economic influences need to be explored. ${ }^{7718}$ Qualitative methods are aptly suited to consider this. While there has been a study considering takeaway owners' and managers' opinions to consumer demand in a low-income neighbourhood of Scotland, there is limited evidence exploring the reasons behind takeaway consumption from consumers. ${ }^{19}$ Consideration of sociocultural issues is essential for the implementation of effective, multi-dimensional intervention strategies.

Therefore, the aim of this research was to explore the sociocultural experiences of takeaway food consumers in Rusholme, Manchester, to gain a deeper understanding of the sociocultural factors involved in takeaway food consumption.

\section{METHODS}

A qualitative perspective was used to explore influences on takeaway food choice. ${ }^{20}$ A constructivist grounded theory (GT) approach was undertaken in order to inform theory in this less widely researched area. GT is a systematic research method that guides the collection and analysis of qualitative data in order to form a theory that is not preconceived by existing theories within the literature, but is 'grounded' within data. ${ }^{21}$ Taking a constructivist methodological perspective to GT allows the investigation of the symbolic meanings that influences the choice to eat takeaway food, along with the processes participants undertake to enact such choices. ${ }^{21}$ In essence, constructivist GT is used to explore social phenomena, ${ }^{22}$ which are known to be involved in the context of food choice. ${ }^{23}$

\section{Ethics and confidentiality}

All participant names used in this report are pseudonyms in order to protect anonymity. Participants were informed of the purpose and nature of the study before consenting.

\section{Patient and public involvement}

No patients were involved in this study and participants were free-living individuals. Participants were not involved in the development of the research question; however, they were central to the inductive nature of this GT research and were involved in the evolution of the interview questions. These results will be disseminated during a community engagement event.

\section{Research setting}

This research conducted in the electoral ward of Rusholme, located two miles south of Manchester City Centre. The majority of Lower-layer Super Output Areas (LSOA) within Rusholme are in the top 31\%-40\% most deprived in England. ${ }^{24}$ In Manchester 26\% of adults and children are classed as obese, higher than the England averages of $23 \%$ and $19.1 \%$, respectively. ${ }^{25}$ Rusholme has a high prevalence of childhood overweight and obesity, with $42.5 \%$ of six-year-old children estimated to be obese. ${ }^{26}$ Rusholme is predominantly residential with a large number of takeaway and restaurant establishments. The population profile comprises of predominantly students and a large mixed ethnic profile of South Asian, Iranian, Kurdish, Lebanese and other Middle Eastern immigrants. ${ }^{27}$

\section{Sampling and recruitment}

Participants were included if they met the following criteria; aged 18-65, consumed takeaway foods at least once per month and resided in Rusholme. Participants were recruited in two ways. First, the study was advertised using a dedicated Facebook page (Facebook Inc., California, USA) and the page was posted into various Facebook groups known to be based in Manchester, including two sports club groups (for all ages) and five university-based societies. Second, a community centre within Rusholme was visited three times during adult social group meetings and children's playgroups and a poster was attached to the community centre board between June 2016 and October 2016. Members of the Facebook groups $(\mathrm{n}=2760)$, and 27 people were directly approached at the community centre. This combined strategy was used to target both students and local residents within Rusholme. Participants were previously not known to the researcher and steps were taken to ensure reciprocity and to address any 'power-imbalance' with agreed interview times and use of simplified but not patronising language. Detailed research logs were kept that evidenced theoretical discussions and personal reflections.

Theoretical (purposive) sampling was used as per grounded theory, ${ }^{22}$ initially using the above selection criteria. Once a number of interviews had taken place, they were transcribed verbatim by hand and data analysed (JB). A theoretical sampling strategy was used based on missing information within nascent categories in order to explore those categories in further depth and to narrow focus. ${ }^{21}$

A subjective judgement of theoretical saturation was employed. Data collection ceased when no new properties were emerging from interviews and were remaining within the scope of the research aims. ${ }^{28}$

\section{Data collection}

\section{Interviews}

One-to-one semi-structured interviews were performed in Rusholme between June and October 2016, carried out by JB, each lasting $30-60 \mathrm{~min}$. A semi-structured interview guide was used and treated as a flexible tool to follow-up leads and develop theoretical categories. ${ }^{21} 2829$ The first interview guide was designed by JB (see online supplementary data file), encompassing topics considered as important, including examples of follow-up questions. 
Follow-up questions were designed to avoid being direct and intrusive questions such as "why do you do that?" Instead, follow-up questions were designed to allude to the 'why', but imply the interviewer's acceptance, such as 'can you tell me more about that?' and 'how does that affect you?' Other follow-up questions were designed to elicit participant's meanings of their terms and feelings about events and situations that they described, as in constructivism. ${ }^{21}$ Finally, questions were designed to elicit information about process and sequence, an important part of GT methodology, ${ }^{29}$ such as 'when...' and 'what happens before and after?"

The interview recordings were anonymised by removing identifying details. Each participant was interviewed once, and the interview was subsequently transcribed.

\section{Data sorting and analysis}

Data sorting and analysis used the GT constant comparative method, moving between the four major processes of coding, memoing, developing categories and theoretical sorting. ${ }^{21} 2930$

Codes were derived from data. Two-step coding was used: initial coding and focused coding. The initial codes were applied to fragments of data, incident by incident. A code was applied for more or less every sentence. The codes were applied by summarising elements such as the actions and processes, feelings, meanings and relationships described by the participant. The coding process also provided an opportunity to indicate questions about data and identify missing information, which were explored in further interviews, that is, the iterative process.

The final process was theoretical sorting where theoretical links were transferred into NVivo 10 (QSR International, Melbourne, Australia). The most significant or frequent codes or groups of codes were then identified and either raised to focused codes or recoded individually. Application of the 'constant comparative' method aided the identification of theoretical links between conceptual categories, their relationships and hierarchical order. These links had been identified during the coding and memoing processes where participants had explicitly or implicitly alluded to them. When a particular order made analytic sense and still remained grounded within data, a theoretical diagram was made..$^{2130-32}$

A sample of the analysis (approximately 50\%) were cross-checked for transparency among the research team to determine whether the codes could be interpreted in the same way. ${ }^{33}$

\section{RESULTS}

Thirteen participants were interviewed. Interviews were carried out in community centres $(\mathrm{n}=3)$, playgroups $(n=5)$ and on a university campus $(n=5)$. Participants' mean age was 38 years $(\mathrm{SD}=13.0)$ and $69 \%$ of participants were women $(n=9)$. Six participants had children (under 18 years old) and four participants did not have children. All participants had been educated to secondary school

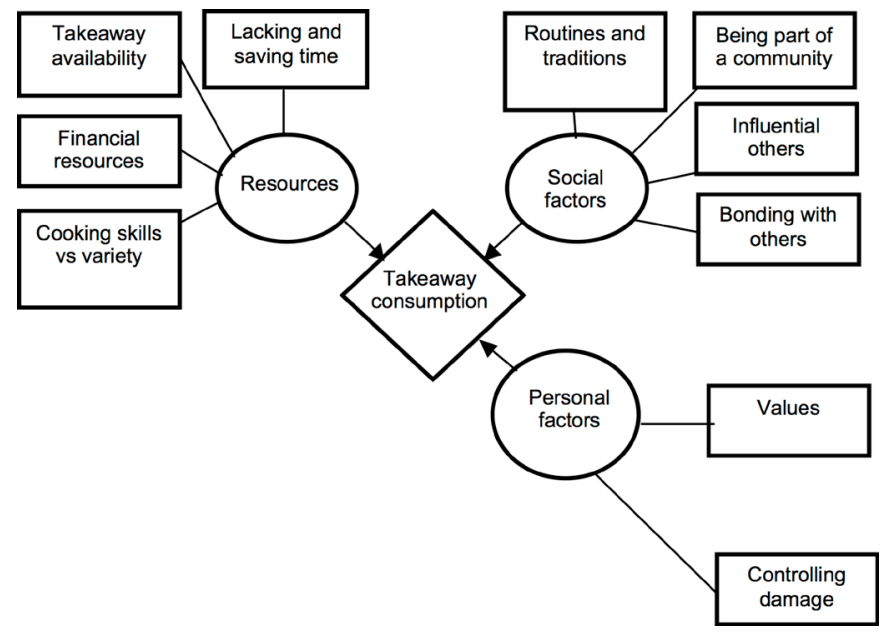

Figure 1 Thematic map of takeaway meal consumption influences.

level with eight either studying for or attained an undergraduate degree or higher. With respect to consumption, $38 \%(\mathrm{n}=5)$ participants ate takeaway food every month, $57 \%(n=7)$ 1-2 times per week, and one participant 3-6 times per week.

Following the analysis, using the constant comparative methods and identifying theoretical links, three superordinate themes were identified and labelled as follows: Social Factors, Personal Factors and Resources, based on the subordinate themes, which are visually represented in figure 1.

\section{Social factors}

Bonding with others

Participants demonstrated how takeaway food supports social relationships, particularly suitable for hedonistic acts of sharing food and as a marker of social belonging and intimacy. They were also an important part of youth night-time drinking culture, used to support social bonding and symbolise hedonism and group identity.

Emma, 26, consumes takeaway food as a way of bonding with an old friend.

It's about bringing people together. That's what it's about isn't it. That's what pizza does for me and Julia'. Emma continued... . 'in terms of people coming together, it's a lot easier for people to be like, come on, let's just chuck a fiver in and get a load of food and share it, as opposed to somebody having to give up a lot of time to cook for a load of people ... there's a lot more preparation involved.

\section{Being part of a community}

Having positive relationships with local takeaway outlet owners was important to a number of participants from a community perspective. Emma recently moved away from her family home to study. She expressed that when she visits home, there are local takeaway outlets that she and her mother regularly visit, with whom they have formed friendly relationships as local customers and local traders: 
in your family environment, there's always that Chinese that you go to. You have your chippy or your Indian or whatever it is. You're usually on first name terms with the people that work there ... She [Emma's mother] knows them, she's on first name terms with them. She gave them a Christmas present.... Because it's your local environment and it's your community.

\section{Routines and traditions}

Consuming takeaway food socially formed an integral part of their regular routines and traditions. Many participants discussed a continuation of such traditions from their childhood; others had formed newer routines with their social network.

Gabby, 55, recounted that eating fish and chips is a longstanding tradition of her working-class family dating back to her childhood: 'Fish and chips on a Friday because that was what you did.'

\section{Influential others}

Gabby discussed the pressure that her stepdaughter and goddaughter experience to be seen by others eating in specific takeaway outlets that were endorsed by celebrities:

I've got a stepdaughter and goddaughter and because they're brought up in the area, there's a lot of peer pressure...Archie's it's called. It's like a burger and shake bar. My goddaughter is 13 and she wants to go there, she doesn't even like burgers but she wants to go and have a shake and be seen in this place.

Emma described that she sometimes feels obliged to eat a takeaway with her mother as she suspects her mother would be offended if she refuses, even though Emma wishes to eat more healthily:

... I don't want to step on my mum's toes and be like 'oh, I'm just going to buy my own food and eat what I like to eat' because she'll get a bit offended by that as well, so.

\section{Personal factors}

Values and controlling damage

Participants described considering a variety of values when making food-decisions, which were linked with the healthiness and guilt of consuming a takeaway such as the quality of the food, variety of ingredients and managing/ reducing portion size. Where participants valued healthy eating, they discussed a method of 'damage control'. If the participants or their children wanted takeaway food, damage control meant still consuming takeaway food but selecting a healthier option.

Robert, a father of two young girls, described his struggle with the dynamics of family food provision. Similarly, he expressed concern for eating healthily and used damage-control methods when getting takeaway food for him and his family:
.... about quantity and quality control ... sometimes you're never quite sure how much is going to turn up when you order something, and so we'll say 'Right, well, there's four of us, let's order for three and see how we get on'... We choose our takeaways. Some, we know we get perhaps a nice salad that comes with it.

Jack described how he attempts to control the healthiness and portion size of takeaway food, as well as the frequency he consumes it; 'If I have to go, I'll go for the least-worst option that I can,... if I can go without it for 2 months it's a bonus...' Jack goes on to describe how he orders dishes that are smaller to limit the amount he consumes; 'I eat the whole thing if I have a take away. I try to (order) small portions as well.'

Amira indicated she accepts eating takeaway food twice per week as she mostly prepares food from scratch.

Because 5, 6 days a week I'm cooking at home, then I don't mind having a cheat twice a week.

Laura, 34, stated that as long as takeaway food was of better quality, then she did not feel as guilty about eating it:

If the food is better quality it seems at least more healthy and then I don't have to feel guilty about eating it.

\section{Resources \\ Lacking or saving time}

The resource category included participants' perceived and not actual time availability that influenced their choice to purchase takeaway food.

This is exemplified by Sonia, a 56-year-old housewife who cooks Indian food daily. Sonia expressed her pleasure with the break from cooking and cleaning that Saturday night takeaway provides:

It's a lot of work at home from scratch . . First there's the cooking it, then there's the cleaning, then there's the smell in the house. There you've just ordered it and you've satisfied what you wanted to eat without the mess! So, I'm thinking takeaways are God-sends really. We even use plastic plates for convenience because a takeaway is just chuck everything in the bin, so there's nothing to wash. And that's great. You don't know how good that feels. When you just eat and just chuck everything in the bin and the kitchen's still tidy.

Participants also cited that they purchased takeaway food when they felt it was too late to cook. A female participant with no children spoke about the lack of regular or appropriate length breaks during her shift work, describing it as too late to cook after a shift:

We rarely get breaks, so for a 6 hour shift, we get a 10 min break and you can't really eat much then, so I don't usually end up eating at work at all. So then right after that shift, obviously you're hungry and 
you've just missed a meal so that's why I end up going to get takeaway... It's too late even bother to cook something.

\section{Takeaway availability}

Participants discussed their exposure to takeaway outlets on travel routes and stated they consumed more takeaway food as a result. Jack exemplified what many of the participants had spoken about during interview:

There are just so many just competing with each other that they're just saturated ... There's no diversity of any kind of health ... Plus, you have 24 hours pizzas now.

\section{Financial resources}

When asked about buying takeaway food, most participants referred to takeaway foods as expensive. The unprompted topic of getting 'value for money' emerged frequently; however, the definitions of 'value for money' were diverse among the sample.

Gabby talks about 'training' her family in portions sizes; however, this is sometimes over-ridden in the case of a takeaway. Gabby referred to her strategy of obtaining the full value of her takeaway by consuming the entire portion, even though she perceives it as too large: '.. a portion size should be no bigger than your palm, like your fist . . . but if my takeaway comes and I paid for it, I'm going to eat it all'. Gabby goes on to describe that her son will save any leftovers for another time if the portion size is too much 'and he will do the same or he'll put it away and later on he'll go and warm it up again'.

Charles did not express any financial hardship. When asked about his thoughts on the price of takeaway food, he associated value for money with food quality:

I just can compare it to where I'm actually from, I think here it is a bit more expensive but I think the quality is bit better. It's not just the food you can buy everywhere, so I think the value for money here is actually quite good.

\section{Cooking skills vs variety}

Nutritional knowledge and cooking skills were mentioned, but the participants desired a variety of food that they could not or did not want to make at home, causing them to seek takeaway foods. Anthony explained that he often cooks for himself and his wife. He comments;

I think it's the variety with a Chinese. It's the fact that you can get duck and things like that - stuff you just wouldn't normally eat and the MSG probably.

\section{DISCUSSION}

This qualitative study of consumers' sociocultural attitudes towards takeaway food consumption revealed several aspects influencing their consumption; similar to other research convenience, time-saving and on-demand access were important themes; however, experiences of social norms, bonding, sharing and a sense of community were also described. To our knowledge, this is the first study in the UK that has uniquely described these sociocultural concepts and the complex interplay of the decision-making process when it comes to takeaway foods.

This study showed that sharing a single takeaway meal was used as a way to bond and affirm relationships, and the large portion sizes generally associated with takeaway foods were well-suited for sharing. Takeaway meals appeared to mark boundaries of inclusion and exclusion in social events such as meeting friends, birthdays, anniversaries etc. and were observed to be markers of social belonging and intimacy. ${ }^{34}$ This is supported by findings previously showing shared fast-food consumption habits among social groups. ${ }^{35}$ The notion of social sharing could be due to the influence of advertisements (consider HungryHouse, JustEat) or the increasing centrality of unhealthy foods in social contexts thus integrating such eating habits into youth culture. ${ }^{36}$

Local commercial areas can represent a place for social interaction ${ }^{37}$ and findings of the present study show outlet owners/employees were considered within this definition of 'community'. The local takeaway provided a sense of belonging and an opportunity for social interaction. Previous research is in support of these findings, suggesting that the sense of community as a result of urban space and neighbourhood layout can enhance feelings of belonging and community identity. ${ }^{38}$ Therefore, residents feel it is not only that they form the local community, but also local businesses including takeaways.

For many of the participants in the study, weekend takeaway consumption had become ingrained into routines and traditions, for example a meal after a night out with friends, fish and chips on a Friday or pizza nights. People develop eating routines ${ }^{39}$ and scripts ${ }^{40}$ in order to simplify daily food decisions. This was described by participants who had traditions dating back to their childhood but also newer traditions within present social settings. It is important to be aware that these routines and traditions form a social function and by doing so legitimises their consumption. $^{41}$

The present research observed that participants took on others eating practices due to established social norms, the influence of others or because of a sense of obligation. ${ }^{42}$ One participant articulated this explaining the perceived pressure from peers to be seen in certain establishments specifically for younger people. Similar reports were found in the study of school children in Tower Hamlets, ${ }^{43}$ which stated not only hunger and value for money but more importantly that their friends were using the fast-food outlets. Adopted social norms and fashions are important influences on food choices and this needs to be considered in terms of why people consume takeaway foods. ${ }^{44}$ Thus any polices and interventions aimed at reducing children's fast-food consumption would need to consider this key influencer. 
Values such as health linked with food quality, variety and portion size were all identified as important in this research, as shown elsewhere in relation to convenience foods. ${ }^{45-47}$ Our research reported the compensatory behaviours, both for themselves and their children, either to limit the 'damage' by making healthier choices at the takeaway or mentally rationalising their behaviour, a finding that is supported by a previous qualitative study. ${ }^{48}$ This enabled participants to partake in indulgent behaviour without experiencing the feelings of guilt associated with such behaviour. This 'compensatory health belief' indicates that people are aware of the negative health effects of takeaway meals. What this does show is that although there is a concern for health among consumers, there is no desire to eliminate takeaway foods from their diet. This contradiction between knowledge and behaviour in relation to fast-food intake has been reported by an Australian qualitative study. ${ }^{49}$ Once again highlighting that health education in itself is not sufficient to change behaviours. ${ }^{50}$

A key subordinate theme emerged around perceived time available for preparing meals. Takeaways were relied on by shift-workers, also highlighted by a report, ${ }^{51}$ in that fast-food outlets tend to be one of the few outlets open late at night. Takeaways were used to make more time available for both essential and non-essential activities and, interestingly, also as a form of weekend respite from usual weekday duties for those most burdened by household tasks. Although fast-food outlets and the workforce have been considered from a feminist perspective, this shows the role they may also place in reducing women's domestic labour. ${ }^{52}$

In the present study, late at night was a key time for consumption where availability of and exposure to takeaway foods is highest and access to healthier, pre-prepared meals is restricted as shown by others investigating proximity of takeaway establishments. ${ }^{53-55}$ Further evidence shows exposure to outlets is positively associated with takeaway consumption, BMI and obesity risk, with evidence of a dose-response effect. ${ }^{56}$ The geographical environment in which individuals exist is proposed to play a pivotal role in shaping food choices; however, the link is not direct. ${ }^{57}$

Participants' financial motivations to buy takeaways appeared to be dependent on two inter-related factors: actual financial resource availability and value for money. The participants who expressed financial hardship tended to associate value for money with the quantity of food, whereas the participants that did not express financial hardship tended to associate value for money with the quality and variety of food. This supports the notion that basic needs are required to be fulfilled (quantity of food) before additional needs can be considered (quality of food). ${ }^{5859}$

This study highlights the sociocultural aspects of takeaway food consumption, which need consideration to develop acceptable and effective interventions and policies. Although planning restrictions will reduce the proliferation of these outlets, that alone may not reduce the consumption. The key features in terms of timesaving, large portion sizes and cost, along with fostering bonds and forming traditions suggest that habits have already been made. Yet one aspect that did not surface in our research was the desire to eat unhealthy food and the omission of this raises the possibility of public health interventions, which encourage the availability of healthier alternatives within the takeaway food sector, through food development, menu planning, menu analysis and training. In order for such intervention to be effective the views and attitudes of takeaway outlet owners and staff would need to be evaluated. Nonetheless, public health interventions should be such to observe the sociocultural aspects of takeaway food consumption.

\section{Strengths and limitations}

A number of strengths of this research should be recognised. First, this is the first study to consider specifically the sociocultural aspects of takeaway consumption. This study uses a very clear definition of takeaway food as opposed to others who have considered either only fast-food or a combination of both. This is particularly important due to the proliferation and abundance of takeaway establishments in the UK. The use of GT methodology in this study has allowed the analysis to remain 'grounded' within data; yet it transcends descriptive accounts and instead accounts for social processes that are happening in data. ${ }^{21}$ The findings are therefore useful in other food choice contexts. However, these findings are specific to the people involved in this study, in particular participants who consumed takeaway food regularly were more likely to relay unsubstantiated opinion and speak for others as such the inherent limitations of qualitative research in wider impact is acknowledge although these findings will resonate with other similar situations and locations.

\section{CONCLUSION}

Numerous local sensitivities have been identified in this study, adding to the evidence base. For example, takeaway meals fostering family bonds, providing respite for mothers, for a sense of familiarity and maintaining cultural norms in an ethnically diverse area of Manchester. These novel findings could suggest that healthier options may satisfy all of these criteria. However, the role of takeaway food as a treat or hedonistic indulgence could mean that healthier alternatives may not reduce their consumption. Public health strategies, including changes to planning applications, need to be flexible and consider the sociocultural phenomena found in the present study to devise effective and acceptable policies.

Acknowledgements The authors wish to thank the participants who contributed their time to this research.

Contributors JB collected data, performed the qualitative analysis and wrote the first draft of the paper. RG designed the methods, secured the funding and directed the qualitative research. SP contributed to the analysis of qualitative data and edited drafts, and IGD contributed to interpretation of data. 
Funding The work presented in this paper was funded by an internal MMU Research Accelerators Grant, and used to fund a Masters by Research project.

Disclaimer The views expressed in the paper are that of the authors and not of any institution or funding body.

Competing interests None declared.

Patient consent for publication Not required.

Ethics approval Manchester Metropolitan University, Hollings Department.

Provenance and peer review Not commissioned; externally peer reviewed.

Data sharing statement Additional data are available by emailing jennyblow1@ outlook.com.

Open access This is an open access article distributed in accordance with the Creative Commons Attribution Non Commercial (CC BY-NC 4.0) license, which permits others to distribute, remix, adapt, build upon this work non-commercially, and license their derivative works on different terms, provided the original work is properly cited, appropriate credit is given, any changes made indicated, and the use is non-commercial. See: http://creativecommons.org/licenses/by-nc/4.0/.

\section{REFERENCES}

1. Butland B, Jebb S, Kopelman P, et al. Tackling obesities: Future choices - project report. Department for Innovation Universities and Skills. 2nd ed. London, 2007.

2. Saunders P, Saunders A, Middleton J. Living in a 'fat swamp': exposure to multiple sources of accessible, cheap, energy-dense fast foods in a deprived community. Br J Nutr 2015;113:1828-34.

3. Jaworowska A, M. Blackham T, Long R, et al. Nutritional composition of takeaway food in the UK. Nutrition \& Food Science 2014;44:414-30.

4. Maguire ER, Burgoine T, Monsivais P. Area deprivation and the food environment over time: A repeated cross-sectional study on takeaway outlet density and supermarket presence in Norfolk, UK, 1990-2008. Health Place 2015;33:142-7.

5. Patterson R, Risby A, Chan MY. Consumption of takeaway and fast food in a deprived inner London Borough: are they associated with childhood obesity? BMJ Open 2012;2:e000402.

6. Smith KJ, McNaughton SA, Gall SL, et al. Takeaway food consumption and its associations with diet quality and abdominal obesity: a cross-sectional study of young adults. Int J Behav Nutr Phys Act 2009;6:29.

7. Adams J, Goffe L, Brown T, et al. Frequency and sociodemographic correlates of eating meals out and take-away meals at home: cross-sectional analysis of the UK national diet and nutrition survey, waves 1-4 (2008-12). Int J Behav Nutr Phys Act 2015;12:51.

8. Manchester City Council. Draft Hot Food Take-Away Supplementary Planning Document, 2016.

9. Department for Communities Local Government. National Planning Policy Framework: Department for Communities and Local Government, 2012.

10. Timperio AF, Ball K, Roberts R, et al. Children's takeaway and fastfood intakes: associations with the neighbourhood food environment. Public Health Nutr 2009;12.

11. Simmons D, McKenzie A, Eaton S, et al. Choice and availability of takeaway and restaurant food is not related to the prevalence of adult obesity in rural communities in Australia. Int $J$ Obes 2005;29:703-10.

12. Turrell G, Giskes K. Socioeconomic disadvantage and the purchase of takeaway food: a multilevel analysis. Appetite 2008;51:69-81.

13. Oexle N, Barnes TL, Blake CE, et al. Neighborhood fast food availability and fast food consumption. Appetite 2015;92:227-32.

14. Laxer RE, Janssen I. The proportion of excessive fast-food consumption attributable to the neighbourhood food environment among youth living within $1 \mathrm{~km}$ of their school. Appl Physiol Nutr Metab 2014;39:480-6.

15. Woodruff RC, Raskind IG, Harris DM, et al. The dietary impact of introducing new retailers of fruits and vegetables into a community: results from a systematic review. Public Health Nutr 2018;21:981-91.

16. Abeykoon AH, Engler-Stringer R, Muhajarine N. Health-related outcomes of new grocery store interventions: a systematic review. Public Health Nutr 2017;20:2236-48.

17. Turrell G, Kavanagh AM. Socio-economic pathways to diet: modelling the association between socio-economic position and food purchasing behaviour. Public Health Nutr 2006;9:375-83.
18. Janssen HG, Davies IG, Richardson LD, et al. Determinants of takeaway and fast food consumption: a narrative review. Nutr Res Rev 2018;31:16-34.

19. Estrade M, Dick S, Crawford F, et al. A qualitative study of independent fast food vendors near secondary schools in disadvantaged Scottish neighbourhoods. BMC Public Health 2014;14:793.

20. Maxwell JA. Qualitative research design: An interactive approach: Sage publications, 2012

21. Charmaz K. Constructing Grounded Theory. London: Sage, 2014.

22. Lingard L, Albert M, Levinson W. Grounded theory, mixed methods, and action research. BMJ 2008;337:a567.

23. Beardsworth A, Keil T. Sociology on the menu: An invitation to the study of food and society. Routledge, 2002.

24. Bullen E. Indices of Deprivation: Mancheter City Council, 2015

25. Public Health England. Manchester unitary authority: Health profile. London: Public Health England, 2015.

26. Public Health England. Obesity Data Tools: Data on child obesity and excess weight at small area level: Public Health England. 2016 http:// webarchive.nationalarchives.gov.uk/20170110165409/https://www. noo.org.uk/visualisation

27. Manchester City Council. Public intelligence population publications. http://www.manchester.gov.uk/downloads/download/4220/public_ intelligence_population_publications

28. Bryant A, Charmaz K. The Sage handbook of grounded theory: Sage, 2007.

29. Glasser B, Strauss A. The discovery of grounded theory: strategies for qualitative research: New York, 1967.

30. Straus A, Corbin J. Basics of qualitative research: Techniques and procedures for developing grounded theory. Thousand Oaks, CA: Sage, 1998.

31. Williams S, Keady J. 'A stony road... a 19 year journey': 'Bridging' through late-stage Parkinson's disease. Journal of Research in Nursing 2008;13:373-88.

32. Tong A, Sainsbury P, Craig J. Consolidated criteria for reporting qualitative research (COREQ): a 32-item checklist for interviews and focus groups. Int J Qual Health Care 2007;19:349-57.

33. Morse JM, Barrett M, Mayan M, et al. Verification strategies for establishing reliability and validity in qualitative research. Int J Qual Methods 2002;1:13-22.

34. Warde A, Martens L. Eating out: Social differentiation, consumption and pleasure: Cambridge University Press, 2000.

35. Cronin JM, McCarthy MB. Fast food and fast games: an ethnographic exploration of food consumption complexity among the videogames subculture. British Food Journal 2011;113:720-43.

36. Stevenson C, Doherty G, Barnett J, et al. Adolescents' views of food and eating: identifying barriers to healthy eating. $J$ Adolesc 2007;30:417-34.

37. Mahmoudi Farahani L, Lozanovska M. A framework for exploring the sense of community and social life in residential environments. International Journal of Architectural Research: ArchNet-IJAR 2014:8:223-37.

38. Mahmoudi Farahani L. The value of the sense of community and neighbouring. Housing. Theory and Society 2016;33:357-76.

39. Bisogni CA, Connors M, Devine CM, et al. Who we are and how we eat: a qualitative study of identities in food choice. $J$ Nutr Educ Behav 2002;34:128-39.

40. Blake CE, Bisogni CA, Sobal J, et al. How adults construct evening meals. Scripts for food choice. Appetite 2008;51:654-62.

41. Warde A. Consumptopn, food and taste: Culinary antinomies and commodity culture. Thousand Oaks, CA: Sage, 1997.

42. Cruwys T, Bevelander KE, Hermans RC. Social modeling of eating: a review of when and why social influence affects food intake and choice. Appetite 2015;86:3-18.

43. Caraher M, Lloyd S, Madelin T. The "School Foodshed": schools and fast-food outlets in a London borough. Br Food $\mathrm{J}$ 2014;116:472-93.

44. Brindal E. Exploring fast food consumption behaviours and social influence PHD Thesis: Univesity of Adelaide South Australia, 2010.

45. In: De Boer M, McCarthy MB, eds. Means-end chain theory applied to Irish convenience food consumers. 83rd EAAE Seminar: Chania (Greece), 2003

46. Ana I, Schoolmeester D, Dekker M, et al. To cook or not to cook: a means-end study of motives for choice of meal solutions. Food Quality and Preference 2007;18:77-88.

47. Kahma N, Mäkelä J, Niva M, et al. Convenience food consumption in the Nordic countries and St. Petersburg area. Int $J$ Consum Stud 2016;40:492-500.

48. Bava CM, Jaeger SR, Park J. Constraints upon food provisioning practices in 'busy' women's lives: trade -offs which demand convenience. Appetite 2008;50:486-98. 
49. Dunn KI, Mohr PB, Wilson CJ, et al. Beliefs about fast food in Australia: a qualitative analysis. Appetite 2008;51:331-4.

50. Aikman SN, Min KE, Graham D. Food attitudes, eating behavior, and the information underlying food attitudes. Appetite 2006;47:111-4.

51. Mason C. Healthy nights. London: Home Office, 2000.

52. Avakian AV, Haber B. From Betty Crocker to feminist food studies: Critical perspectives on women and food: Liverpool University Press, 2005.

53. Fraser LK, Edwards KL, Cade J, et al. The geography of Fast Food outlets: a review. Int J Environ Res Public Health 2010;7:2290-308.

54. Moore LV, Diez Roux AV, Nettleton JA, et al. Fast-food consumption, diet quality, and neighborhood exposure to fast food: the multi-ethnic study of atherosclerosis. Am J Epidemiol 2009;170:29-36.

55. Cetateanu A, Jones A. Understanding the relationship between food environments, deprivation and childhood overweight and obesity: evidence from a cross sectional England-wide study. Health Place 2014;27:68-76.

56. Burgoine T, Forouhi NG, Griffin SJ, et al. Associations between exposure to takeaway food outlets, takeaway food consumption, and body weight in Cambridgeshire, UK: population based, cross sectional study. BMJ 2014;348:g1464.

57. Sobal J, Bisogni CA, Devine CM, et al. A conceptual model of the food choice process over the life course. Frontiers in Nutritional Science 2006;3:1.

58. Bourdieu P. Distinction: A social critique of the judgement of taste. London: Routledge \& Kegan Paul, 1984.

59. Savage $\mathrm{M}$, Longhurst $\mathrm{B}$, class $\mathrm{S}$. consumption and the influence of Bourdieu. In: Edgell S, Hetherington K, Warde A, eds. Consumption matters. Oxford: Blackwell Publishers, 1996. 